\title{
Relação entre o Grau de Severidade de Queimadas e Focos de Calor no Município de São Pedro do Piauí, Brasil
}

\author{
Relation between the Degree of Severity of Burnings and Hot Spots in the \\ Municipality of São Pedro do Piauí, Brazil
}

\section{Relación entre el Grado de Severidad de Quemaduras y Focos de Calor en el Municipio de São Pedro do Piauí, Brasil}

\author{
Grenda Juara Alves Costa ${ }^{1}$ \\ Lucas Almeida Monte ${ }^{2}$ \\ Emanuel Lindemberg Silva Albuquerque ${ }^{3}$
}

\begin{abstract}
RESUMO: O estudo objetiva avaliar a relação entre o grau de severidade de queimadas e os focos de calor no município de São Pedro do Piauí, estado do Piauí, a partir do índice espectral NDBR (Índice de Queimada Normalizada), considerando o recorte temporal de 2006 a 2016. Os procedimentos metodológicos contemplam revisão bibliográfica e aquisição da base cartográfica do recorte espacial e temporal da pesquisa. Utilizou-se os registros dos focos de calor obtidos no Banco de Dados de Queimadas (BDQueimadas - INPE) e imagens de satélites obtidas na USGS (United States Geological Survey), dos anos de 2006 e 2016, no intuito de calcular o índice espectral NBR (Índice de Queimada Normalizada). Constatou-se um total de 4.857 focos de calor na área em análise, sendo que há uma predominância dos registros no segundo semestre do ano, particularmente entre os meses de julho a dezembro, sendo que o ápice é o mês de outubro. Ao considerar o índice espectral NDBR, utilizando como referência o mês de agosto de 2006 e 2016, o município de São Pedro do Piauí não teve setores classificados com: alta moderada severidade, alta severidade e nem anomalias, sendo que boa parte do município foi classificada com alta regeneração.
\end{abstract}

PALAVRAS-CHAVE: Queimadas. Focos de calor. Sensoriamento remoto.

\footnotetext{
${ }^{1}$ Universidade Federal de Pernambuco - UFPE. Av. Prof. Moraes Rego, 1235 - Cidade Universitária, Recife - PE, 50670-901. grendajuara@hotmail.com.

${ }^{2}$ Universidade Federal do Piauí - UFPI Campus Universitário Ministro Petrônio Portella - Bairro Ininga - Teresina - PI - CEP: 64049-550. lucasmonte-geo@hotmail.com.

${ }^{3}$ Universidade Federal do Piauí - UFPI Campus Universitário Ministro Petrônio Portella - Bairro Ininga - Teresina - PI - CEP: 64049-550. lucasmonte-geo@hotmail.com. lindemberg@ufpi.edu.br.
} 
Relação entre o Grau de Severidade de Queimadas e Focos de Calor no Município de São Pedro do...

ABSTRACT: The objective of this study is to evaluate the relation between the severity of burnings and the heat sources in the city of São Pedro do Piauí, state of Piauí, based on the spectral index NDBR (Normalized Burn Ratio) considering the temporal clipping 2006 to 2016. The methodological procedures include bibliographical revision and acquisition of the cartographic base of the spatial and temporal clipping of the research. The records of the heat sources obtained in the Burning Database (BDQueimadas - INPE) and satellite images from the USGS (United States Geological Survey), from 2006 and 2016, were used to calculate the NBR spectral index (Normalized Burn Index). It was observed a total of 4,857 hot spots in the area under analysis, with a predominance of records in the second half of the year, particularly between the months of July and December, with the peak being the month of October. When considering the spectral index NDBR, using as reference the month of August of 2006 and 2016, the municipality of São Pedro do Piauí did not have sectors classified with: high moderate severity, high severity and nor anomalies, being that much of the municipality was classified with high regeneration.

KEYWORDS: Burning. Hot spots. Remote sensing.

RESUMEN: El estudio objetiva evaluar la relación entre el grado de severidad de quemaduras y los focos de calor en el municipio de São Pedro do Piauí, estado del Piauí, a partir del índice espectral NDBR (Índice de Quemada Normalizada), considerando el recorte temporal de 2006 a 2016. Los procedimientos metodológicos contemplan revisión bibliográfica y adquisición de la base cartográfica del recorte espacial y temporal de la investigación. Se utilizaron los registros de los focos de calor obtenidos en el Banco de Datos de Quemadas (BDQuemadas - INPE) e imágenes de satélites obtenidas en la USGS (de los Estados Unidos Geológicos), de los años 2006 y 2016, con el fin de calcular el índice espectral NBR (Índice de Quemado Normalizado). Se constató un total de 4.857 focos de calor en el área en análisis, siendo que hay un predominio de los registros en el segundo semestre del año, particularmente entre los meses de julio a diciembre, siendo que el ápice es el mes de octubre. Al considerar el índice espectral NDBR, utilizando como referencia el mes de agosto de 2006 y 2016, el municipio de São Pedro do Piauí no tuvo sectores clasificados con: alta moderada severidad, alta severidad y ni anomalías, siendo que buena parte del municipio fue clasificada con alta regeneración.

PALABRAS-CLAVE: Quemaduras. Focos de calor. Detección remota.

\section{INTRODUÇÃO}

Desde os primórdios da civilização humana e, expressivamente, com a ocupação empreendida pelos colonizadores, ocorreu uma superexploração dos recursos naturais, sobretudo da cobertura vegetal, sequenciado, em muitas ocasiões, pelo uso predatório e indiscriminado das queimadas (GOMES; MEDEIROS; ALBUQUERQUE, 2010).

Ao considerar que a queimada se encaixa em uma categoria de risco, é importante destacar que a mesma é um objeto social (VEYRET; MESCHINET DE RICHEMOND, 2007), sendo definido como a percepção do perigo, ou seja, da possível catástrofe acontecer, a 
exemplo das queimadas em áreas urbanas ou rurais. De acordo com Melo, Melo Souza e Ross (2016) os riscos são ameaças evidentes para o ambiente, tendo em vista a probabilidade de um determinado evento (ameaça) acontecer, sobretudo quando envolve o ser humano.

Ao analisar as características fisionômicas e florísticas do Nordeste brasileiro, aliada à fragilidade e vulnerabilidade dos sistemas ambientais frente aos processos de uso e ocupação da terra (SOUZA, 2000), nota-se a priori uma maior incidência de queimadas, consequentemente na ocorrência de focos de calor, que foram registrados na última década do século XXI no estado do Piauí, aliado as secas recorrentes na região (ALBUQUERQUE, 2017).

De acordo com Gonçalves (2005) e Silva Filho, Teles e Santos Neto (2009), as queimadas correspondem a uma técnica de preparo do solo, que utiliza a aplicação do fogo de maneira controlada, em tese, para a limpeza do terreno, no intuito de eliminar restos de vegetais, favorecendo a disponibilidade de nutrientes no solo para aumentar sua capacidade de plantio. Por sua vez, o termo foco de calor é utilizado para o registro da ocorrência do fogo na superfície terrestre, obtido por meio das técnicas de sensoriamento remoto.

Corrobora-se que Jensen (2009) define que o sensoriamento remoto é a arte e a ciência de obter informações de um objeto sem estar em contato físico com ele, podendo ser usado para medir e monitorar importantes características biofísicas e atividades humanas na Terra, por meio da captação da radiação eletromagnética refletida e emitida pela superfície, a exemplo do mapeamento do grau de severidade e sua relação com os focos de calor, estudo em pauta na pesquisa em epígrafe. Desta forma, o sensoriamento remoto utiliza a radiação eletromagnética refletida e emitida por uma superfície para registrar suas características.

Vale salientar que uma imagem é subdividida em pixels, os quais constituem uma área mínima na superfície imageada pelo sensor e com localização espacial definida, para as quais foram registrados os valores digitais referentes à intensidade da energia refletida e captada em diferentes faixas do espectro eletromagnético (NOVO, 2010), configurando deste modo um modelo digital de uma determinada área.

Melo, Melo Souza e Amador (2016) destacam que a modelagem de dados constitui um procedimento teórico que envolve um conjunto de técnicas com a finalidade de compor um quadro simplificado e inteligível de um determinado ambiente ou fenômeno, consistindo em um artifício que reflete a abstração da realidade no plano computacional.

Para Batista (2013) é de extrema importância a utilização de imagens de satélite para o monitoramento de áreas queimadas, já que esta técnica possui grande eficiência, englobando, na análise dos dados, extensas porções territoriais. Nesse sentido, a rapidez e eficácia na detecção e monitoramento dos incêndios florestais são fundamentais para o 
Relação entre o Grau de Severidade de Queimadas e Focos de Calor no Município de São Pedro do...

controle do fogo, bem como a redução dos custos nas operações de combate e diminuição de danos ambientais.

Florenzano (2007) afirma que a importância da detecção das queimadas transcende a ocorrência dos focos de calor em si, uma vez que o sensoriamento remoto orbital constitui um importante sistema de monitoramento ambiental, sobretudo quando associado ao mapeamento de incêndios florestais e na identificação de áreas desmatadas.

Nessa perspectiva, o estudo em epígrafe objetiva avaliar a relação entre o grau de severidade de queimadas e os focos de calor no município de São Pedro do Piauí, estado do Piauí, a partir do índice espectral NDBR (Índice de Queimada Normalizada), considerando o recorte temporal de 2006 e 2016. Dessa forma, almeja-se quantificar e qualificar esses dados dentro do contexto progressivo e/ou regressivo, no intuito de configurar cenários tendenciais e potencializar a tomada correta de decisões por parte dos órgãos competentes.

Menciona-se que o índice NDBR foi desenvolvido por Koutsias e Karteris (1998), com o objetivo de identificar áreas queimadas, sendo que a nomenclatura e o desenvolvimento da análise multitemporal foi idealizado por Key e Benson (1999), a partir de técnicas de sensoriamento remoto (ROSAN; ALCANTARA, 2015).

Dessa forma, é importante frisar que quanto maior a atividade fotossintética na folha vegetal, maiores serão as feições de absorção nas faixas do espectro relativos às regiões do azul e do vermelho e, portanto, mais expressivos serão os seus valores. Não obstante, à medida que ocorre a diminuição ou ausência da unidade foliar, as feições de absorção do azul e do vermelho vão desaparecendo, sendo que os registros são nitidamente perceptíveis nos índices espectrais (BAPTISTA, 2004).

\section{MATERIAL E MÉTODO}

\section{Área de Estudo}

A área em estudo compreende o município de São Pedro do Piauí, localizado no estado do Piauí (Figura 1), sendo que este município ocupa uma área territorial de 527,86 quilômetros quadrados e uma população de 13.639 habitantes, com base no último censo realizado pelo IBGE (2010).

Menciona-se que o município de São Pedro do Piauí ocupa a posição $42^{a}$ dentre os 224 municípios do Piauí, no tocante às cidades com maiores números de habitantes no estado (Figura 2). Em comparação com outros municípios do Brasil, fica na posição 2.392a , dentre os 5.570 municípios. Sua densidade demográfica (hab./ $\mathrm{km}^{2}$ ) é de 26,32 , colocando-o 
na posição $33^{\underline{a}}$ no estado. Quando comparado com outros municípios no Brasil, fica na posição 2.598ª (IBGE, 2010).

Figura 1 - Mapa de localização do município de São Pedro do Piauí

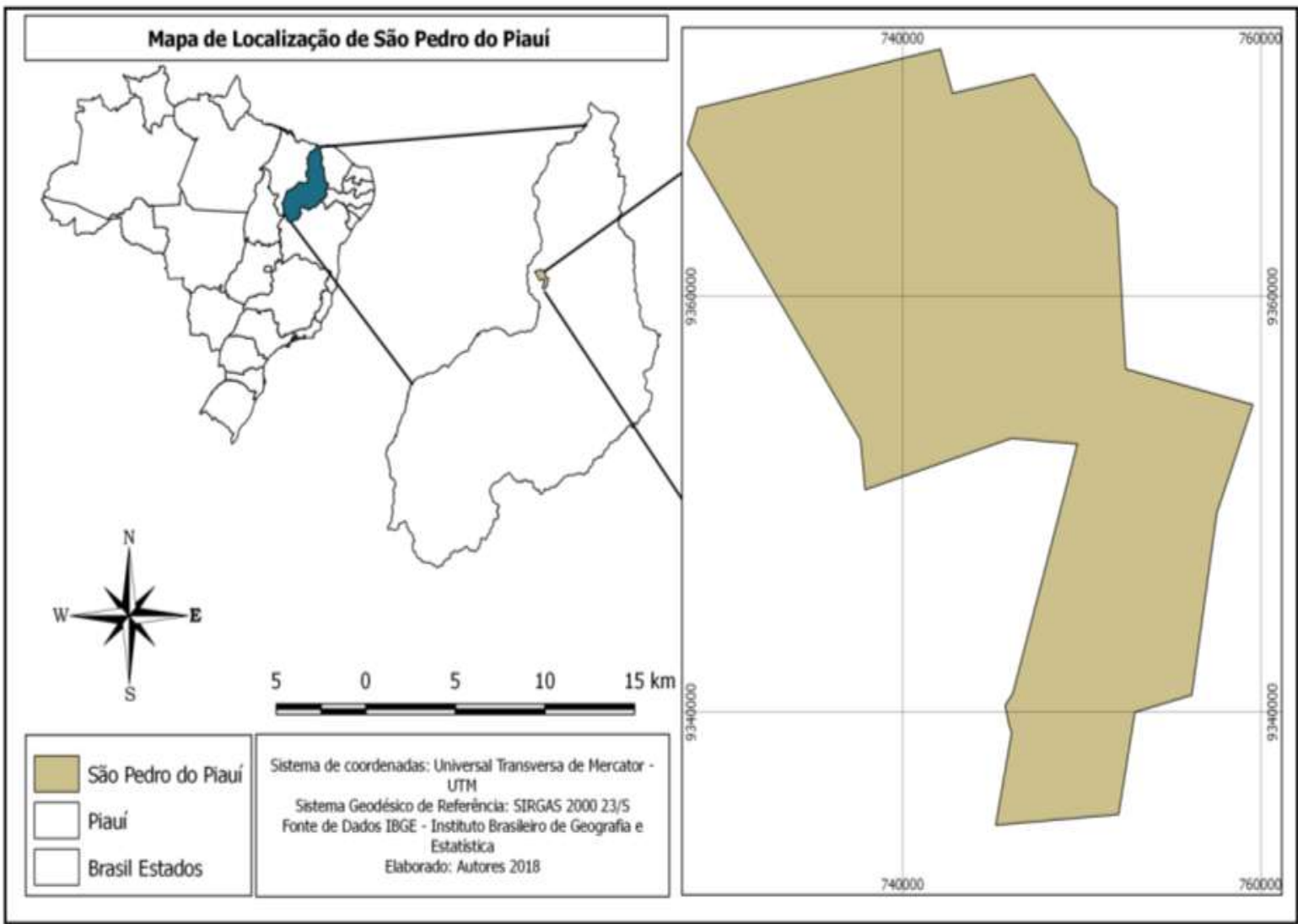

Fonte: IBGE, 2012.

Figura 2 - Área central do município de São Pedro do Piauí

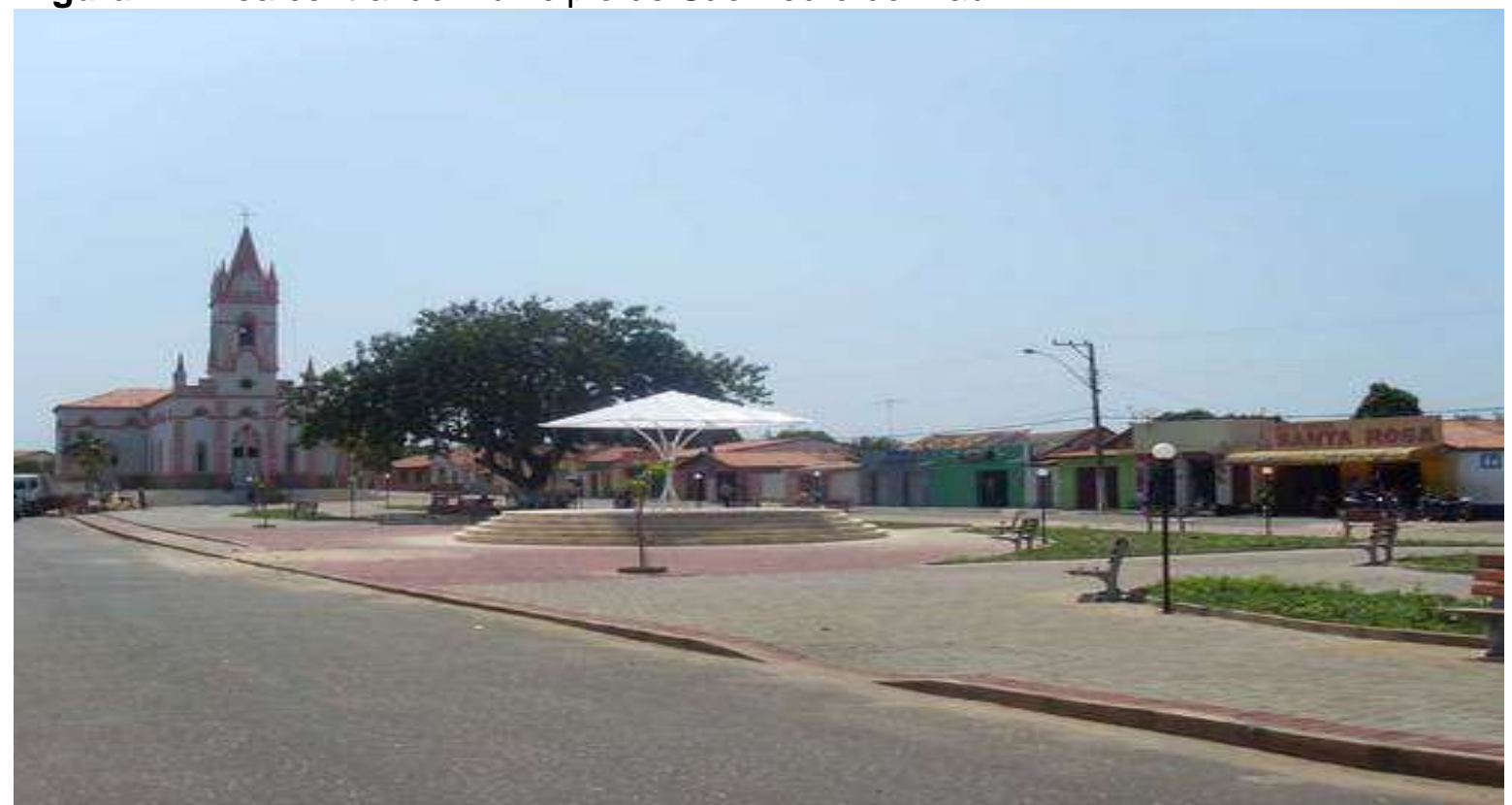

Coordenada UTM/Datum SIRGAS2000 E= 752577; N= 9344075. Fonte: São Pedro do Piauí (2017). 
Relação entre o Grau de Severidade de Queimadas e Focos de Calor no Município de São Pedro do...

Ao considerar os aspectos fisiográficos do município de São Pedro do Piauí, de acordo com Jacomine (1986) e Aguiar e Gomes (2004), constata-se que a área em estudo encontra-se assentada, do ponto de vista geológico, na Bacia Sedimentar do Parnaíba, com destaque para as formações: Pedra de Fogo (arenitos, folhelhos, calcários e silexitos) e Corda (arenitos, argilitos e folhelhos) (AGUIAR; GOMES, 2004).

O clima é caracterizado como subúmido seco, com excedente hídrico moderado no verão. A rede de drenagem principal é a bacia hidrográfica do Rio Parnaíba, compreendendo os setores do Médio Parnaíba Piauiense (PIAUÍ, 2010). As formas de relevo da área em análise são compostas por superfícies tabulares, com relevo plano a suavemente ondulado, com altitudes variáveis entre 150 e 300 metros (AGUIAR; GOMES, 2004).

Os solos encontrados no município são derivados de alterações dos arenitos, dos siltitos, dos folhelhos, dos calcários, dos argilitos e lateritos, derivando solos com características, principalmente, litólicos, hálicos e distróficos, apresentando textura média, pouco desenvolvido, rasos a muitos rasos, associado à vegetação transicional entre caatinga e cerrado (PFALTZGRAFF; CARVALHO; RAMOS, 2010).

\section{PROCEDIMENTOS METODOLÓGICOS E OPERACIONAIS}

Os procedimentos metodológicos para análise, caracterização dos focos de calor e cálculo do índice espectral de queimadas por diferença normalizada (NDBR) tiveram início com o levantamento bibliográfico e cartográfico da área em estudo. O levantamento bibliográfico permitiu identificar e avaliar a melhor metodologia, considerando as particularidades do recorte espacial e temporal da pesquisa, destacando as contribuições de: Assad e Sano (1998), Ferreira (2004), Baptista (2006), Florenzano (2007), Miller e Thode (2007), Novo (2010), Silva e Baptista (2015), entre outros.

Foram priorizadas e utilizadas imagens, dados e softwares disponibilizados gratuitamente, ou com licença registrada, trabalhando na perspectiva de gerar informações úteis e pertinentes que dessem subsídios exitosos e executáveis para avaliar a relação entre o grau de severidade de queimadas e os focos de calor no município de São Pedro do Piauí.

Os dados georreferenciados foram obtidos através de download no site do (INPE) Instituto Nacional de Pesquisas Espaciais (2017), através do Banco de Dados de Queimadas, em formato shapefile, com destaque para os satélites polares NOAA-15, NOAA-16, NOAA-17, NOAA-18 e NOAA-19, equipados com o sensor Advanced Very High Resolution Radiometer (AVHRR).

De acordo com Florenzano (2007), as imagens do sensor AVHRR são muito utilizadas para detectar focos de incêndio, uma vez que permite identificar e localizar, em tempo real, 
focos de fogo ativo em todo o território brasileiro, respeitando as configurações de captura por sensoriamento remoto, tendo em vista que é um satélite do tipo polar de baixa altura.

Corrobora-se que os satélites mencionados possuem múltiplos usos, dentre os quais: i) avaliar a distribuição da temperatura sobre o mar e a terra; ii) indicar condições meteorológicas e agrometeorológicas; iii) identificar área queimada por meio dos canais adicionais (região do visível e infravermelho) e iv) monitorar queimadas, mostrando-se muito útil na identificação das ocorrências dos focos de calor, considerando os princípios e as resoluções (espacial, temporal, radiométrica e espectral) do sensoriamento remoto orbital.

É válido lembrar que somente frentes de fogo com mais de 30 metros de diâmetro são passíveis de serem detectadas pelo sensor, e que a presença de nuvens e o sombreamento das árvores interferem diretamente na detecção dos focos de calor. Deste modo, salienta-se que a quantidade de focos de calor detectada representa apenas uma fração da real ocorrência (SILVA FILHO; TELES; SANTOS NETO, 2009), mas destaca-se que estes dados são os que mais se aproximam da realidade dentro do escopo temporal da pesquisa.

De posse dos dados obtidos no Banco de Dados de Queimadas do Instituto Nacional de Pesquisas Espaciais (2017), procedeu-se na sequência com as seguintes etapas:

- Reprojeção dos dados ao sistema UTM / SIRGAS 2000;

- Criação do banco de dados geográfico (BDFocosCalor) em formato shapefile, com geometria pontual;

- Tabulação dos dados (focos de calor) para o recorte espacial da pesquisa;

- Quantificação anual dos registros e;

- Espacialização e geração dos mapas através dos focos de calor para os anos de 2006 e 2016, considerando todos os registros obtidos entre o dia 1ำ de janeiro a 31 de dezembro de cada ano em análise.

Para a geração do NDBR do município de São Pedro do Piauí, foram utilizadas imagens orbitais do satélite Landsat 8, sensor OLI (Operational Land Imager), com resolução de 30 metros, órbita 219, ponto 64, que foram adquiridas pelo site da United States Geological Survey (USGS), do ano de 2016 (datada de 25 de agosto de 2016) e Landsat 5, TM (Thematic Mapper) do ano de 2006 (datada de 13 de agosto de 2006).

A identificação das áreas queimadas foi mapeada a partir do índice NDBR, sendo que o mesmo foi desenvolvido por Koutsias e Karteris (1998), utilizando a nomenclatura e o desenvolvimento da análise multitemporal realizado por Key e Benson (1999). O cálculo do NBR se dá através da resposta espectral de áreas de queimadas no infravermelho próximo (pnir) e infravermelho médio (pmir), conforme é retratado na Equação 1 (KOUTSIAS; KARTERIS, 1998). 
Relação entre o Grau de Severidade de Queimadas e Focos de Calor no Município de São Pedro do...

$$
N B R A=\pi r^{2}=\frac{p_{N I R}-P_{M I R}}{p_{N I R}+p_{M I R}}
$$

Salienta-se que as bandas do infravermelho próximo e infravermelho médio apresentam o melhor contraste entre uma vegetação fotossinteticamente saudável e uma vegetação queimada, além disso verifica-se o aumento da reflectância no infravermelho próximo e a diminuição da reflectância no infravermelho médio em situações de queimadas. Após os cálculos do pré-fogo e pós-fogo, foi feita a diferença entre ambos, resultando no NDBR, que é dado pela Equação 2.

$$
N D B R=N B R_{\text {pré }}-N B R_{\text {pós }}
$$

Para diferenciação das áreas, considerando a vegetação saudável e a vegetação queimada, foi aplicada a renderização de falsa-cor, pois ela mostra a intensidade das variações ocorridas na área, sendo que a escala adotada compreende o intervalo com valores que variam de 0 a 1 , sendo que quanto mais próximo de 1 mais intensa foram os danos na cobertura vegetal. Por sua vez, a classificação da severidade das queimadas foi realizada de acordo com a classificação proposta por Key e Benson (1999), sendo que os valores obtidos são multiplicados por 1033, conforme é retratado no Quadro 1.

Quadro 1 - Níveis de severidade e variações dos valores do $\triangle$ NBR

\begin{tabular}{|l|l|}
\hline NíVEL DE SEVERIDADE & VARIAÇÃO DO $\mathbf{A N B R}$ \\
\hline Alta Regeneração & $-500 \mathrm{a}-251$ \\
\hline Baixa Regeneração & $-250 \mathrm{a}-101$ \\
\hline Não queimado & $-100 \mathrm{a}+99$ \\
\hline Baixa Severidade & $+100 \mathrm{a}+269$ \\
\hline Baixa Moderada Severidade & $+270 \mathrm{a}+439$ \\
\hline Alta Moderada Severidade & $+440 \mathrm{a}+659$ \\
\hline Alta Severidade & $+660 \mathrm{a}+1350$ \\
\hline Anomalia & $>+1350$ \\
\hline
\end{tabular}

Fonte: adaptado de Rosan e Alcântara (2015).

Dessa forma, no intuito de espacializar tais dados, vale destacar que um Sistema de Informação Geográfica (SIG) pode ser utilizado nas mais diversas perspectivas que englobam os estudos territoriais, bem como na pesquisa da previsão de determinados fenômenos ou no apoio a decisões de planejamento, considerando a concepção de que os dados armazenados representam um modelo do mundo real (BURROUGH, 1987). 
Conforme Lang e Blaschke (2009), os SIGs fornecem valiosas contribuições no apoio às tarefas e aos projetos de planejamento e ordenamento territorial, que a cada dia tornamse mais complexos e robustos diante dos avanços tecnológicos, tendo em vista que essa ferramenta proporciona a otimização das informações por meio de consultas espaciais e tabulares, como nos estudos que tratam da relação entre o grau de severidade de queimadas e os focos de calor.

É importante salientar que o mapeamento dos focos de calor, a geração do mapa de calor, do processamento de imagens para execução dos dados referentes ao pré-fogo, pósfogo e NDBR do município de São Pedro do Piauí, foram realizados em ambiente de Sistemas de Informações Geográficas (SIGs), utilizando recursos dos softwares QGIS 2.18.9 (plataforma livre) e ArcGIS 10.2 (com licença registrada na Universidade Federal do Piauí - UFPI).

Vale salientar que o sistema de projeção cartográfica utilizado no estudo correspondeu ao Universal Transversal de Mercator (UTM), tendo como referencial geodésico o Sistema de Referência Geocêntrico para as Américas (SIRGAS2000), sendo este o datum oficial adotado no Brasil. Destaca-se que a área em estudo engloba, do ponto de vista da Geodésia, a Zona 23 Sul do sistema de projeção adotado.

\section{RESULTADOS E DISCUSSÃO}

$\mathrm{Na}$ perspectiva de realizar a análise espaço-temporal das ocorrências de focos de calor no município de São Pedro do Piauí, estado do Piauí, no recorte temporal adotado (2006 a 2016), e no intuito de quantificar e qualificar as informações obtidas dentro do contexto progressivo e/ou regressivo, os dados vetoriais das ocorrências foram processados em ambiente de Sistema de Informação Geográfica (SIG), atrelado a um banco de dados que foi estruturado na pesquisa.

Dessa forma, de acordo com os dados coletados, constatou-se um total de 4.857 focos de calor no município em pauta. A figura 3 retrata a quantidade de focos detectados durante cada ano em análise.

Ao analisar qualitativamente os dados mencionados, corrobora-se que as maiores quantidades de focos de calor foram detectadas no período de julho a dezembro no recorte temporal realizado para a pesquisa, compreendendo exatamente os meses mais quentes nessa porção territorial do Nordeste brasileiro, sendo que o ápice dos registros foi identificado no mês de outubro de cada ano. Por outro lado, é importante salientar que foram mínimos ou quase inexistentes os focos de calor no período de janeiro a junho, o qual corresponde ao período chuvoso e mais úmido na região. 
Figura 3 - Focos de calor de 2006 a 2016 no município de São Pedro do Piauí

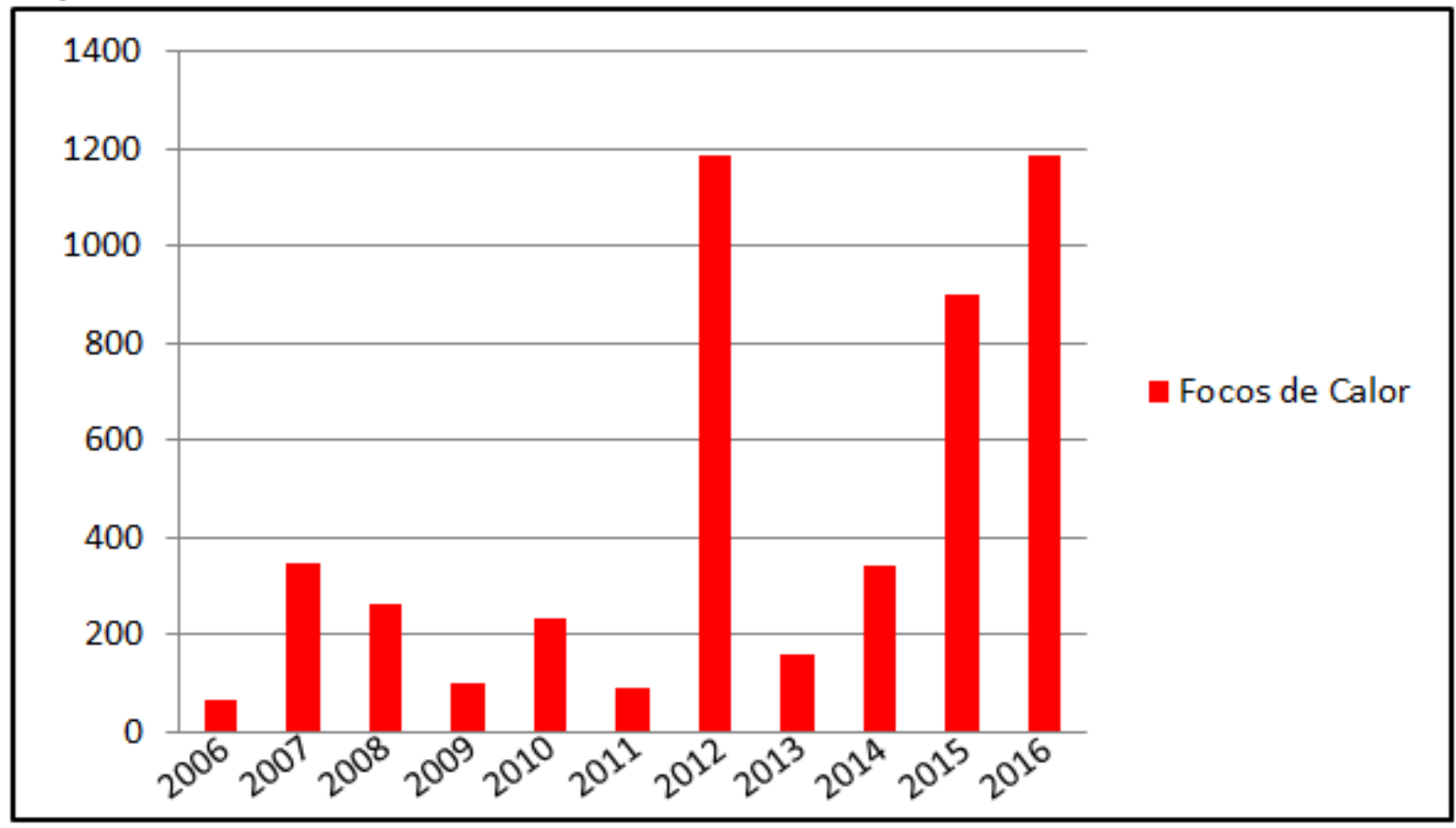

Elaborado pelos autores (2018).

De acordo com Souza (2000), no regime pluviométrico do semiárido é grande a variação que se manifesta ao longo do período chuvoso, bem como nos totais anuais das chuvas entre diferentes anos em uma mesma localidade, sendo que a estação chuvosa tem duração de três a cinco meses e o período seco é de sete a nove meses.

Ao analisar espacialmente os dados obtidos, verifica-se que as ocorrências dos focos de calor se estenderam, primordialmente, na área central e na parte sul do município (Figura 4), sendo que em alguns anos o setor norte do município também foi bastante atingido. Nesse sentido, é possível observar que nos anos de 2007, 2012, 2015 e 2016 os números de focos de calor foram expressivos para todo o município em epígrafe.

Diante do exposto, menciona-se que os anos de 2012 e 2016 foram os que mais se destacaram dentro do recorte temporal da pesquisa, tendo em vista os elevados registros obtidos. Nestes anos foram identificados 1.187 e 1.184 focos de calor, respectivamente, no município de São Pedro do Piauí, sendo que os maiores acontecimentos ocorreram, exatamente, entre os meses de agosto a dezembro, com destaque para o mês de outubro, que registrou 543 ocorrências em 2012, e 900 ocorrências em 2016. Do ponto de vista proporcional, os anos de 2012 e 2016 superaram em mais de $95 \%$ os dados de 2006 , ou seja, um aumento expressivo ao considerar o recorte espacial e temporal em análise.

Corrobora-se que a classificação da severidade das queimadas possibilita entender diretamente os efeitos da pertubação, principalmente sobre a sobrevivência e a estrutura da vegetação dominante (SILVA; BAPTISTA, 2015), sendo de fundamental importância a 
utilização de índices espectrais para avaliar o grau de severidade das áreas atingidas pela queimada.

Figura 4 - Mapa de focos de calor de 2006 a 2016 em São Pedro do Piauí

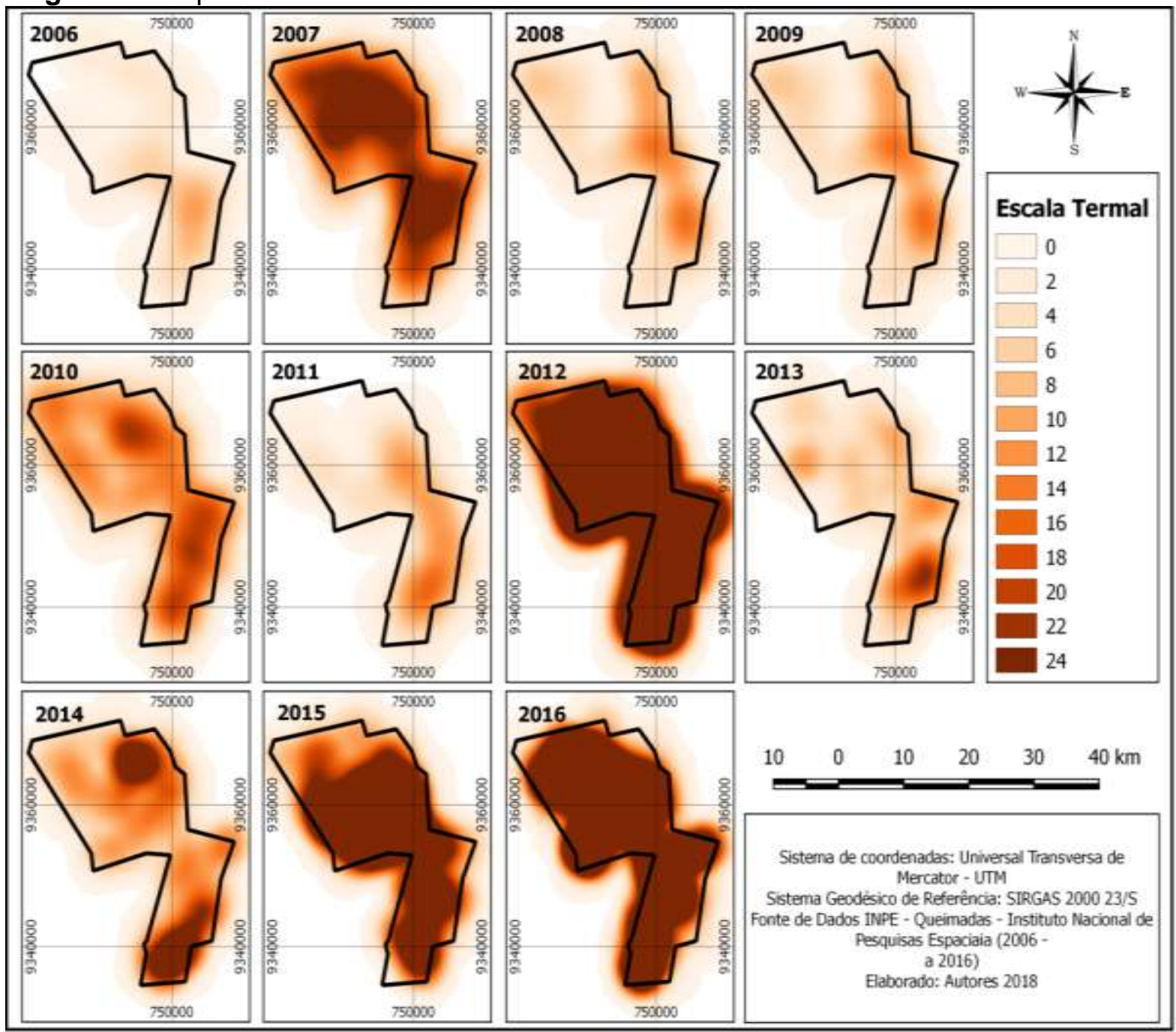

Fonte: Instituto Nacional de Pesquisas Espaciais (2017).

De acordo com a figura 5, há uma nítida e exorbitante diferença entre os anos de 2006 e 2016, considerando o resultado obtido. Ao realizar o cruzamento do índice NBR com os dados dos focos de calor, na perspectiva de validar tal informação, constata-se que no ano de 2016 o índice NBR detectou alto grau de vegetação queimada, logo coincidindo com os dados de queimadas para o mesmo ano, no qual foram detectados 1.184 , sendo um dos mais elevados no recorte em análise.

Destaca-se que ao comparar os dados de focos de calor com os dados obtidos através dos cálculos de NBRs para os anos em análise, é possível verificar a enorme diferença sofrida na vegetação durante o período estudado, particularmente no segundo semestre do ano. Este fato é justificado pelo registro de elevadas temperaturas no estado do Piauí, associado à influência de sua tropicalidade e aliado à irregularidade temporal e 
Relação entre o Grau de Severidade de Queimadas e Focos de Calor no Município de São Pedro do...

espacial das chuvas no ambiente semiárido brasileiro e área de entorno, o que tende a ser um potencializador para o aumento dos incêndios florestais/queimadas, e que são quantificados como focos de calor pelos sensores remotos.

Figura 5 - Índice NBR de 2006 e 2016 para o município de São Pedro do Piauí

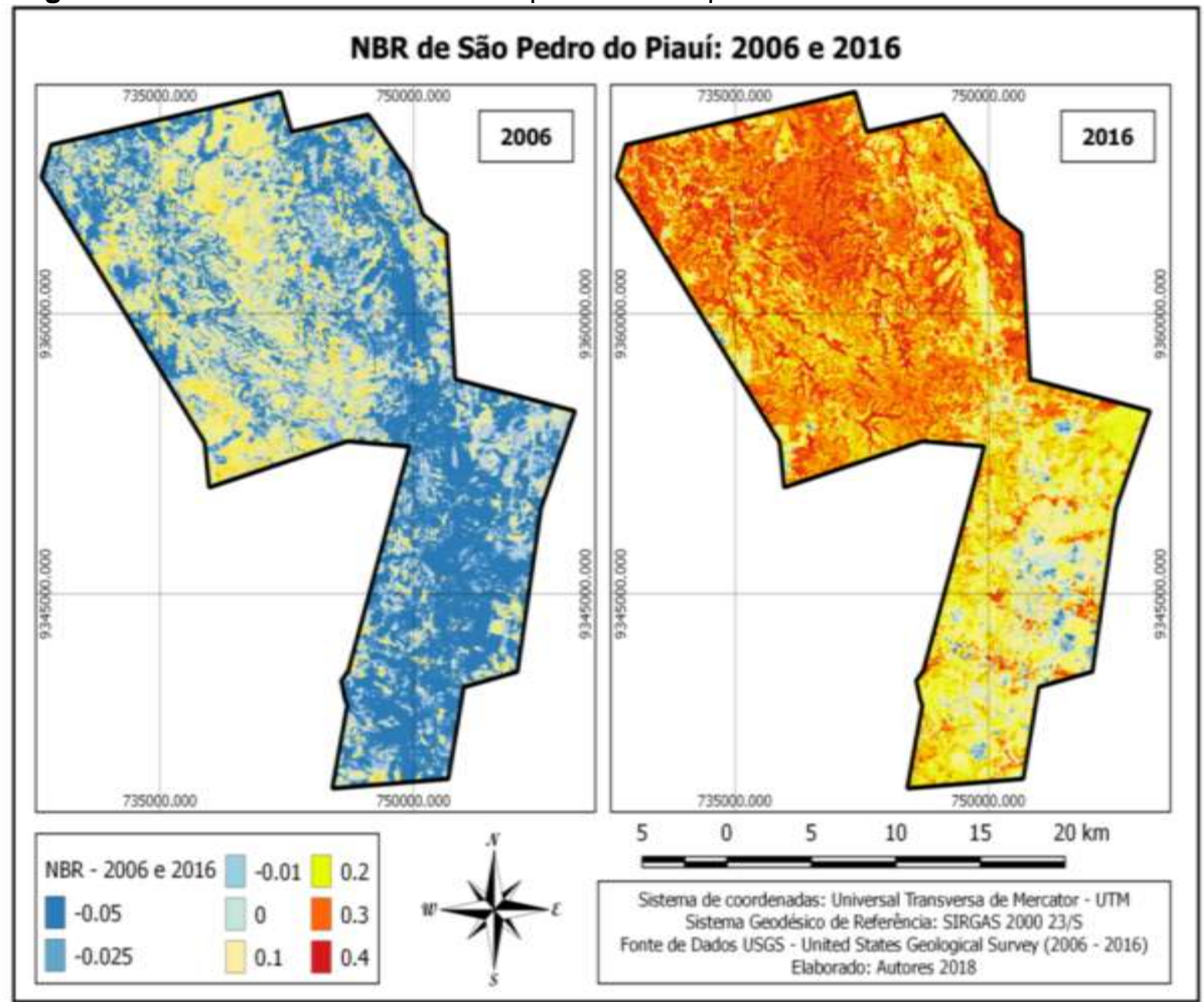

Fonte: USGS (2017).

No intuito de analisar o resultado do índice espectral NDBR para os anos de 2006 e 2016, foi realizada a classificação a partir do grau de regeneração da cobertura vegetal, seguida do cruzamento entre os anos em destaque, sendo que esta análise foi dividida em oito categorias, a saber: alta regeneração, baixa regeneração, não queimado, baixa severidade, baixa moderada severidade, alta moderada severidade, alta severidade e anomalia, conforme pode ser visualizada na figura 6 .

Diante da análise empreendida, é possível visualizar que apesar de a diferença entre os anos de 2006 e 2016 ser grande, ao considerar o índice espectral NDBR, o município de São Pedro do Piauí não teve setores classificados com: alta moderada severidade, alta severidade e nem anomalias. Por outro lado, constata-se que boa parte do município foi classificada com alta regeneração, ou seja, a vegetação identificada como queimada em 
2006 se regenerou em 2016, o que representa um excelente indicador ambiental que deve ser mantido nos anos vindouros, conforme é possível visualizar nas figuras 7 e 8.

Figura 6 - Índice NDBR de 2006 e 2016 para o município de São Pedro do Piauí

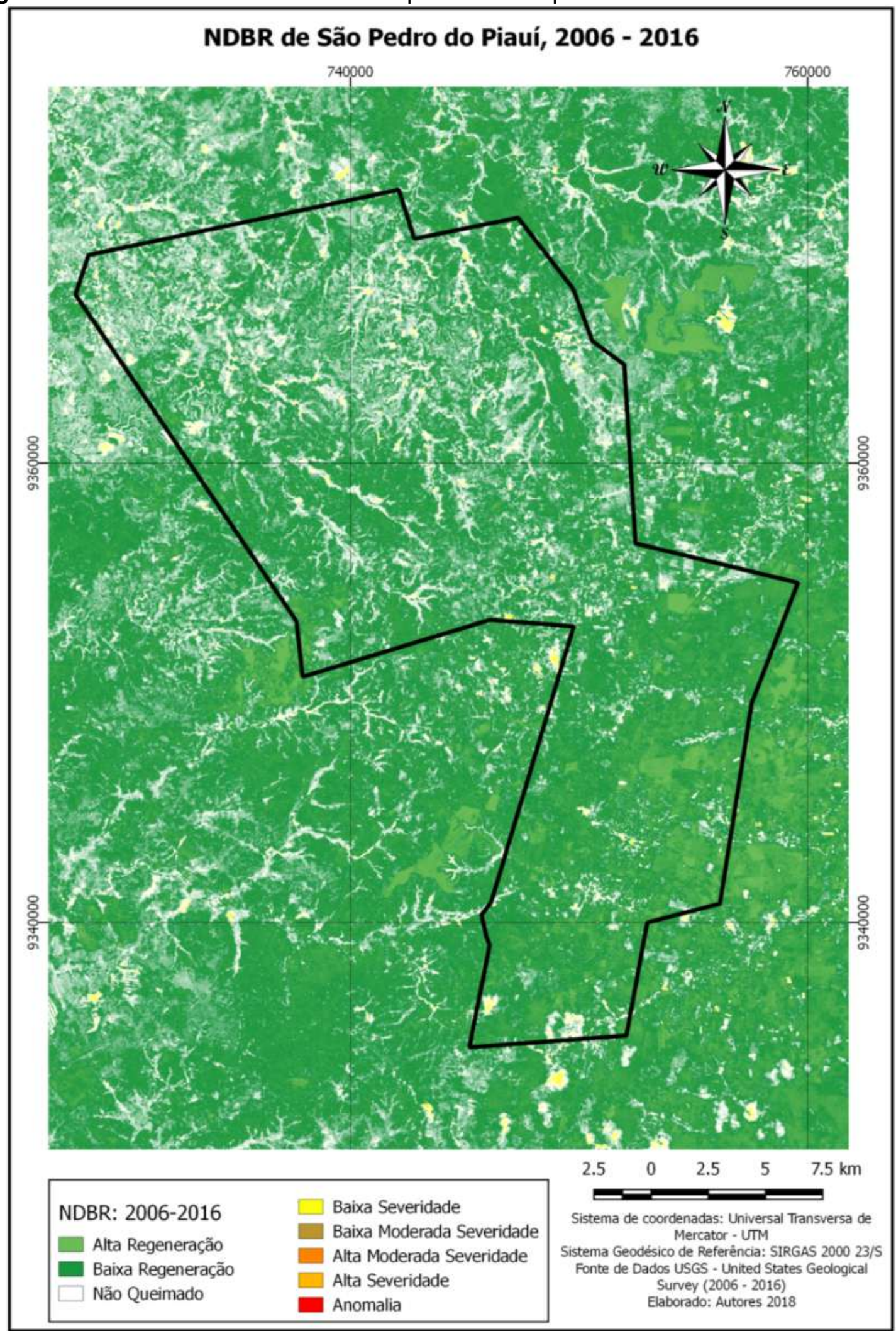

Fonte: USGS (2017). 
Figura 7 - Área de regeneração florestal no setor sul do município de São Pedro do Piauí

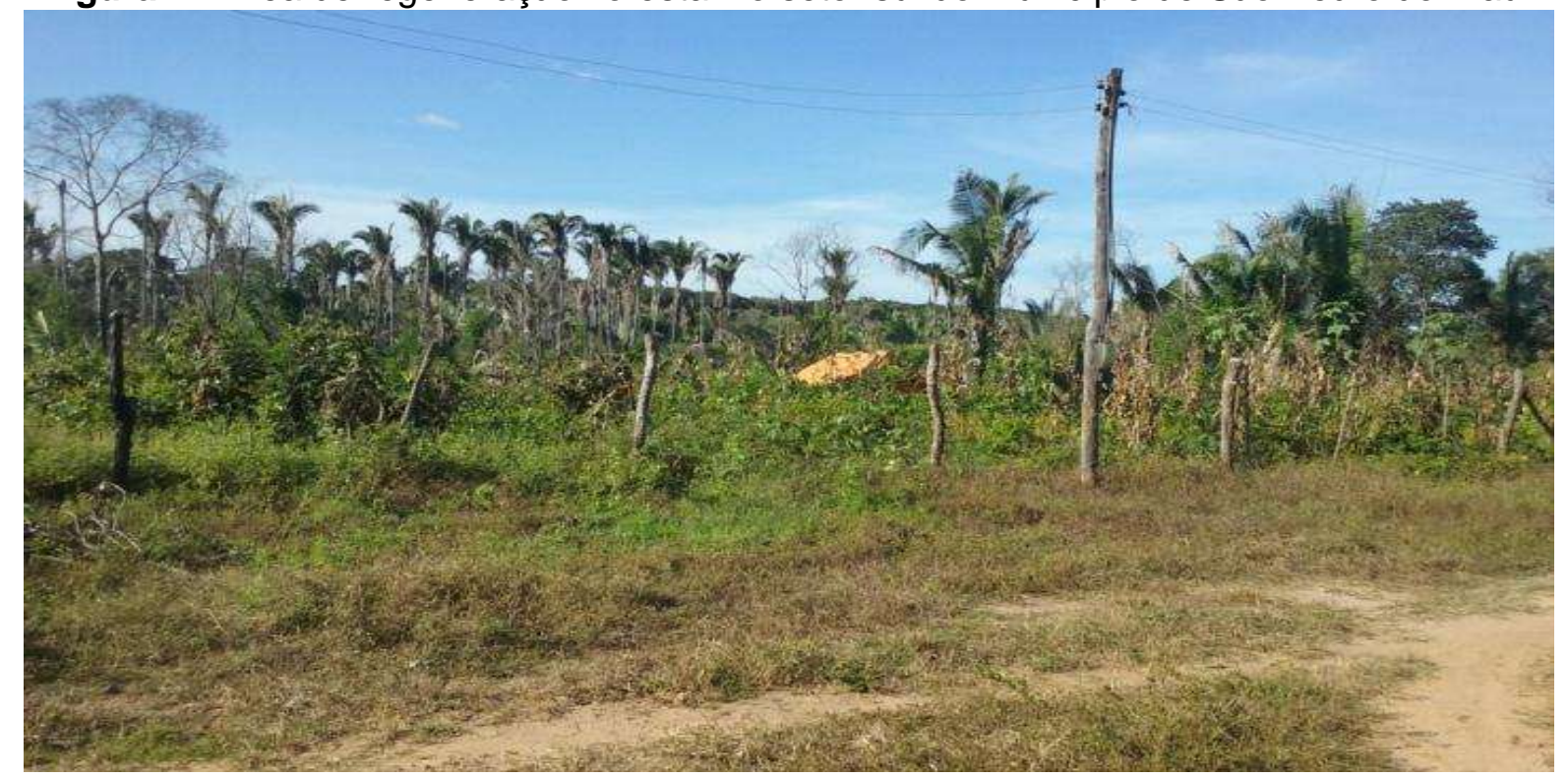

Coordenada UTM/Datum SIRGAS2000 E= 754936; N= 9347929. Fonte: Albuquerque (2017).

Figura 8 - Área de regeneração florestal no setor norte do município de São Pedro do Piauí

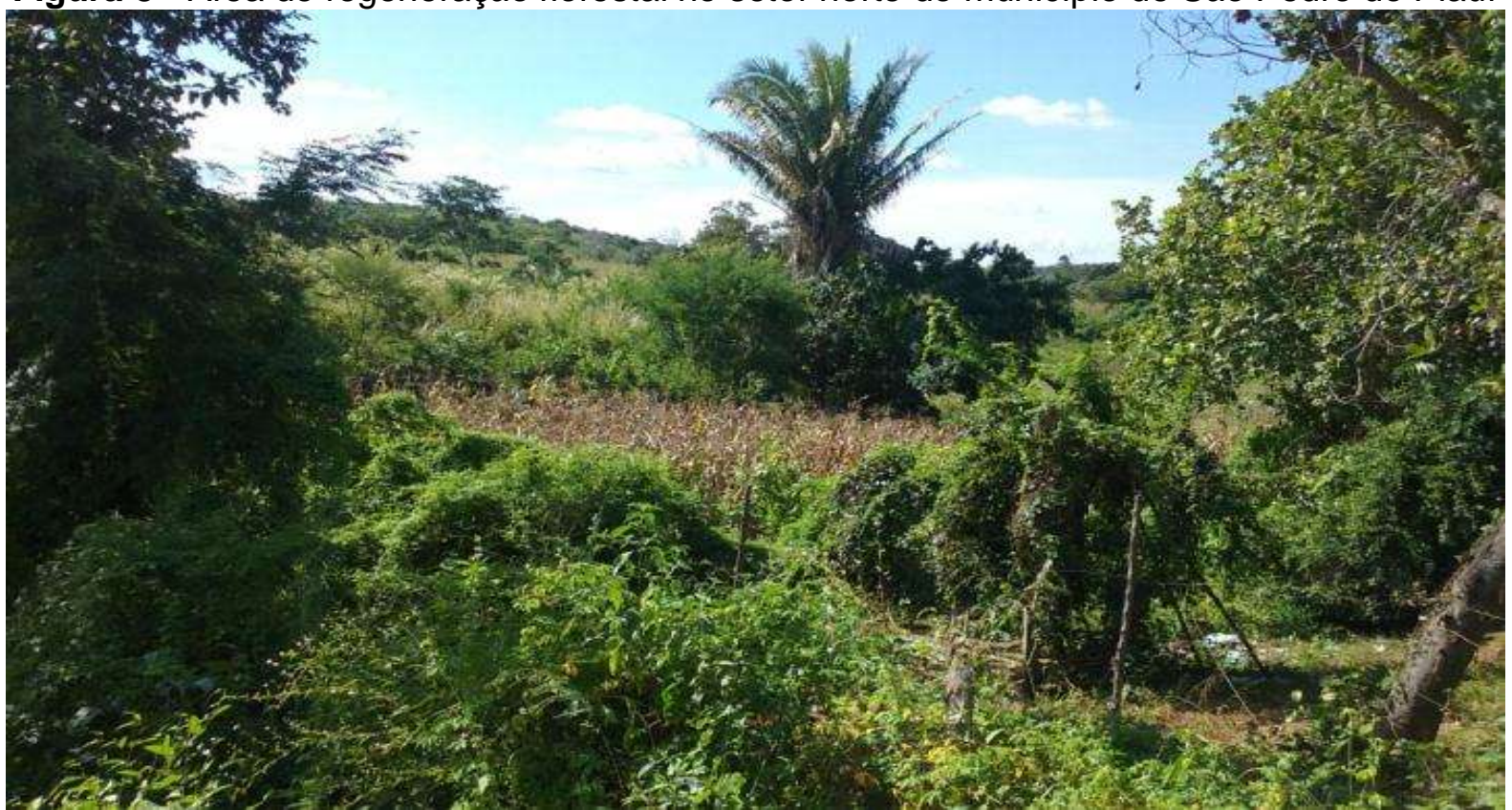

Coordenada UTM / Datum SIRGAS2000 E= 741826; N= 9354294. Fonte: Albuquerque (2017).

Nesse contexto, ao sublinhar o recorte espacial e temporal da pesquisa ao viés ambiental, esta análise possibilita a identificação dos locais onde há os maiores e os menores índices na regeneração da cobertura florestal, sendo que este consiste em um importante indicador direcionado ao planejamento territorial.

A análise espacial empreendida possibilita a realização de importantes interpretações que permeiam o espaço geográfico, sendo possível configurar os cenários das ocorrências dos focos de calor no município de São Pedro do Piauí, podendo assim subsidiar, conforme 
os dados apresentados, a tomada correta de decisões por parte dos órgãos ambientais competentes, tanto a nível municipal, quanto estadual.

\section{CONSIDERAÇÕES FINAIS}

No que concerne aos objetivos almejados na compreensão entre o grau de severidade de queimadas e sua relação com os focos de calor no município de São Pedro do Piauí, estado do Piauí, foram identificados 4.857 focos de calor obtidos pelos sensores disponibilizados no banco de dados do (INPE) Queimadas, considerando os anos de 2006 a 2016. (INSTITUTO NACIONAL DE PESQUISAS ESPACIAIS, 2017).

Ao considerar o recorte espacial, o ano de 2006 foi o que obteve os menores registros, sendo que as ocorrências dos focos de calor se estenderam de julho a dezembro, com uma maior concentração na área central e sul do município. A partir de 2007 , verifica-se um aumento dos focos, sendo que foram identificados registros em praticamente toda a área do município. Por sua vez, destaca-se que os anos de 2012 e 2016 foram o que mais se destacaram no recorte temporal da pesquisa, totalizando, respectivamente, 1187 e 1184 focos de calor.

Ao considerar a relação entre o grau de severidade de queimadas e os focos de calor no município de São Pedro do Piauí, é nítida essa relação por meio do índice espectral NBR (Índice de Queimada Normalizada). Por outro lado, ao analisar o NDBR dos anos extremos da pesquisa, ou seja, 2006 (menores registros de focos de calor) e 2016 (maiores registros de focos de calor), este município não teve setores classificados com alta moderada severidade, alta severidade e nem anomalias, constatando-se que a área em epígrafe pode ser classificada como de alta regeneração quanto à sua cobertura vegetal.

Em síntese, constatou-se que os registros encontram-se agrupados, sobretudo, no segundo semestre do ano (julho a dezembro), sendo que as maiores incidências de focos de calor, no recorte espacial e temporal adotado, concentram-se no mês de outubro. É importante frisar que no primeiro semestre do ano (janeiro a junho), os dados são insignificantes, uma vez que este corresponde ao período chuvoso e/ou mais úmido nessa porção do Nordeste brasileiro.

Com base nos dados e considerando o processo histórico de uso e ocupação da terra na Região Nordeste, é possível afirmar que esta concentração de focos de calor no segundo semestre do ano se dá em virtude, sobretudo, da tradição secular do preparo da terra para o plantio no ano vindouro, em que a limpeza do terreno é sequenciada pela queima.

É válido lembrar que os registros obtidos não contemplam a quantidade exata de queimadas que existiram in $10 c o$, tendo em vista que a presença de nuvens e o sombreamento das árvores podem interferir diretamente na detecção dos focos de calor, 
Relação entre o Grau de Severidade de Queimadas e Focos de Calor no Município de São Pedro do...

associada ainda às características de resolução (espacial, temporal, espectral e radiométrica) do satélite/sensor utilizado. Não obstante, esse cenário é o que mais se aproxima da realidade das ocorrências de focos de calor registrados no município de São Pedro do Piauí.

Por sua vez, é importante salientar que outras possibilidades de análises e interpretações podem ser realizadas para o mesmo recorte espacial e temporal da pesquisa, sobretudo quanto ao uso de imagens com outras características de resolução em sensoriamento remoto.

\section{REFERÊNCIAS}

AGUIAR, R. B. de; GOMES, J. R. de C. (Org.). Projeto cadastro de fontes de abastecimento por água subterrânea: Estado do Piauí: diagnóstico do município de São Pedro do Piauí. Fortaleza: CPRM: Serviço Geológico do Brasil, 2004. Disponível em: http://rigeo.cprm.gov.br/xmlui/bitstream/handle/doc/16504/Rel_SaoPedrodoPiaui.pdf?sequen $\mathrm{ce}=1$. Acesso em: 9 nov. 2018.

ALBUQUERQUE, E. L. S. Focos de calor na bacia hidrográfica do Rio Poti (Ceará/Piauí) a partir dos registros do satélite Noaa-18. In: PEREZ FILHO, A.; AMORIM, R. R. Os desafios da Geografia Física na fronteira do conhecimento. Campinas, SP: Instituto de Geografia/UNICAMP, 2017. p. 4708-4719.

ASSAD, E. D.; SANO, E. E. Sistemas de informações geográficas: aplicações na agricultura. Brasília: EMBRAPA, 1998.

BAPTISTA, G. M. M. Mapeamento do sequestro de carbono e de domos urbanos de CO2 em ambientes tropicais, por meio de sensoriamento remoto hiperespectral. Geografia, Rio Claro, v. 29, p. 189-202, 2004.

BAPTISTA, G. M. M. Sensoriamento remoto hiperespectral: o novo paradigma nos estudos de solos tropicais. Brasília: Universa, 2006.

BATISTA, A. C. Detecção de incêndios florestais por satélites. [Curitiba]: Universidade Federal do Paraná, 2013. Disponível em: http://www. floresta.ufpr.br/firelab/wpcontent/uploads/2013/09/artigo16.pdf. Acesso em: 15 maio 2017.

BURROUGH, P. A. Principles of geographical information systems for land resources assessment. Oxford: Claredon Press, 1987.

FERREIRA, N. J. Detecção de queimadas com o uso radiômetro AVHRR. In: FERREIRA, N. J. (Org.). Aplicações ambientais brasileiras dos satélites NOAA e TIROS-N. São Paulo: Oficina de Textos, 2004. p. 41-56.

FLORENZANO, T. G. Iniciação em sensoriamento remoto. São Paulo: Oficina de Textos, 2007.

GOMES, D. D. M.; MEDEIROS, C. N. de; ALBUQUERQUE, E. L. S. Análise têmporoespacial das ocorrências de focos de calor no estado do Ceará: configuração dos cenários no contexto das unidades fitogeográficas e das macrorregiões de planejamento. Fortaleza, CE: Instituto de Pesquisa e Estratégia Econômica do Ceará - IPECE, 2010. (Texto para discussão, 90).

GONÇALVES, J. dos S. A prática da queimada no saber tradicional e na concepção científica de risco: Estudo sobre o uso do fogo por pequenos produtores rurais do norte do 
estado de Minas Gerais. 2005. Dissertação (Mestrado em Extensão Rural) - Universidade Federal de Viçosa, MG, Viçosa, 2005.

IBGE. Cidades e Estados. Área territorial oficial dos Estados e Municípios Brasileiros. 2012. Disponível em:

http://www.ibge.gov.br/home/geociencias/cartografia/default_territ_area.shtm. Acesso em: 15 out. 2018.

IBGE. Cidades. 2010. Disponível em: http://www.cidades.ibge.gov.br. Acesso em: 19 jan. 2018.

INSTITUTO NACIONAL DE PESQUISAS ESPACIAIS- INPE. Programa de Monitoramento de Focos. Dados pontuais de focos de calor. 2017. Disponível em:

http://sigma.cptec.inpe.br/queimadas/. Acesso em: 10 jun. 2017.

JACOMINE, P. K. T. Levantamento exploratório: reconhecimento de solos do Estado do Piauí. Rio de Janeiro: EMBRAPA: SNLCS/SUDENE, 1986.

JENSEN, J. R. Sensoriamento remoto do ambiente. São José dos Campos, SP:

Parênteses, 2009.

KEY, C. H.; BENSON, N. Measuring and remote sensing of burn severity: the $\mathrm{CBI}$ and NBR. 1999. Disponível em:

http://nrmsc.usgs.gov/files/norock/products/SEVER36_im_copy6.pdf. Acesso em: 25 jun. 2017.

KOUTSIAS, N.; KARTERIS, M. Logistic regression modelling of multitemporal thematic mapper data for burned area mapping. International Journal of Remote Sensing, Basingstoke, GB, v. 19, p. 3499-3514, 1998.

LANG, S.; BLASCHKE, T. Análise da paisagem com SIG. São Paulo: Oficina de Texto, 2009.

MELO, F. P. de; MELO SOUZA, R.; AMADOR, M. B. M. Fenômenos geofísicos, captados a partir de sensores orbitais: estimativa de temperatura na superfície de Garanhuns-PE.

Caderno de Geografia, Belo Horizonte, v. 26, n. 45, p. 95-112, 2016.

MELO, F. P. de; MELO SOUZA, R.; ROSS, J. L. S. Modelagem de geoformas para mitigação do risco geoambiental em Garanhuns-PE. ACTA Geográfica, Boa Vista, v. 10, n. 22, p. 87-105, jan./abr. 2016.

MILLER, J. D.; THODE, A. E. Quantifying burn severity in a heterogeneous landscape with a relative version of the delta Normalized Burn Ratio (dNBR). Remote Sensing of

Environment, New York, US, v. 109, n. 1, p. 66-80, jul. 2007.

NOVO, E. M. L. de M. Sensoriamento remoto: princípios e aplicações. São Paulo: Blücher, 2010.

PFALTZGRAFF, P. A. dos S.; CARVALHO, L. M. de; RAMOS, M. A. B. Introdução. In: PFALTZGRAFF, P. A. dos S.; TORRES, F. S. de M.; BRANDÃO, R. de L. (org.).

Geodiversidade do Estado do Piauí. Recife: CPRM, 2010. p. 9-14.

PIAUÍ. Secretaria do Meio Ambiente e Recursos Hídricos. Plano Estadual de Recursos Hídricos. Relatório síntese. Teresina, PI: SEMAR, 2010.

ROSAN, T. M.; ALCÂNTARA, E. Detecção de áreas queimadas e severidade a partir do índice espectral $\triangle$ NBR. In: SIMPÓSIO BRASILEIRO DE SENSORIAMENTO REMOTO SBSR, 17., 2015, João Pessoa, PB. Anais [...]. João Pessoa: SBSR, 2015. p. 526-533.

SÃO PEDRO DO PIAUÍ. Prefeitura Municipal. Notícias. Disponível em: http://saopedrodopiaui.pi.gov.br/saopedrodopiaui. Acesso em: 1 out. 2017. 
SILVA FILHO, E. B. da; TELES, L. de J. S.; SANTOS NETO, L. A. dos. Ocorrências de focos de calor no estado de Rondônia em 2007. Sociedade \& Natureza, Uberlândia, MG, v. 21 n. 2, p. 123-140, ago. 2009.

SILVA, S. L. da; BAPTISTA, G. M. de M. Análise do grau de severidade de áreas queimadas na estação ecológica de águas emendadas por meio de dados do Landsat 8. Revista

Brasileira de Geografia Física, Recife, PE, v. 8, n. 2, p. 431-438, 2015.

SOUZA, M. J. N. de. Bases naturais e esboço do zoneamento geoambiental do estado do Ceará. In: SOUZA, M. J. N. de; LIMA, L. C.; MORAIS, J. O. de (org.). Compartimentação territorial e gestão regional do Ceará. Fortaleza, CE: FUNECE, 2000. p. 13-98.

USGS. Earth Explorer. Earth Resources Observation and Science (EROS). Center. Data Center. 2017. Disponível em: https://earthexplorer.usgs.gov/. Acesso em: 26 jul. 2017.

VEYRET, Y.; MESCHINET DE RICHEMOND, N. O risco, os riscos. In: VEYRET, Y. (org.)

Os riscos: o homem como agressor e vítima do meio ambiente. São Paulo: Contexto, 2007.

Recebido: outubro de 2018. Aceito: janeiro de 2019. 